\title{
Modelling land use dynamics in socio-ecological systems: A case study in the UK uplands
}

\author{
Mette Termansen ${ }^{\mathrm{a}}$, Daniel S. Chapman ${ }^{\mathrm{b}}$, Claire H. Quinn ${ }^{\mathrm{c}}$, Evan D.G. Fraser ${ }^{\mathrm{d}}$, Nanlin \\ Jin $^{\mathrm{e}}$, Nesha Beharry-Borg ${ }^{\mathrm{f}}$, Klaus Hubacek ${ }^{\mathrm{g}, \mathrm{h}}$ \\ a)Food and Resource Economics, University of Copenhagen, Frederiksberg C, Denmark

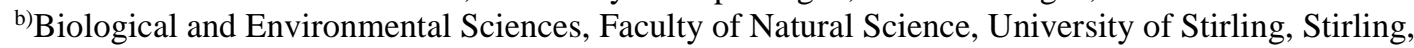 \\ United Kingdom \\ ${ }^{c}$ Sustainability Research Institute, School of Earth and Environment, University of Leeds, Leeds, \\ United Kingdom \\ d)Department of Geography, Environment, and Geomatics, University of Guelph, Guelph, ON, Canada \\ e)Department of Computer and Information Sciences, Northumbria University, Newcastle upon Tyne, \\ United Kingdom \\ ${ }^{\text {f) }}$ Centrascape Mid Centre Mall Compound, Chaguanas, Trinidad \\ g) Center for Energy and Environmental Sciences (IVEM), Energy and Sustainability Research Institute \\ Groningen (ESRIG), University of Groningen, Groningen, The Netherlands \\ h)International Institute for Applied Systems Analysis, Laxenburg, Austria
}

\begin{abstract}
It is well-recognised that to achieve long-term sustainable and resilient land management we needs to understand the coupled dynamics of social and ecological systems. Land use change scenarios, will often aim to understand $i$ ) the behaviours of land management, influenced by direct and indirect drivers, ii) the resulting changes in land use and iii) the environmental implications of these changes. While the literature in this field is extensive, approaches to parameterise coupled systems through integration of empirical social science based models and ecology based models still need further development. We propose an approach to land use dynamics modelling based on the integration of behavioural models derived from choice experiments and spatially explicit systems dynamics modelling. This involves the specification of a choice model to parameterise land use behaviour and the integration with a spatial habitat succession model.
\end{abstract}

We test this approach in an upland socio-ecological system in the United Kingdom. We conduct a choice experiment with land managers in the Peak District National Park. The elicited preferences forms the basis for a behavioural model, which is integrated with a habitat succession model to predict the landscape level vegetation impacts. The integrated model allows us to create projections of how land use may change in the future under different environmental and policy scenarios, and the impact this may have on landscape vegetation patterns. We illustrate this by showing future projection of landscape changes related to hypothetical changes to EU level agricultural management incentives.

The advantages of this approach are, (i) the approach takes into account potential environmental and management feedbacks, an aspect often ignored in choice modelling, (ii) the behavioural rules are revealed from actual and hypothetical choice data, which allows the research to test the empirical evidence for various determinants of choice, (iii) the behavioural choice models generates probabilities of alternative behaviours which makes them ideally suited for integration with simulation models. 
The paper concludes that the modelling approach offers a promissing route for linking socio-economic and ecological features of socio-ecological systems. Furthermore, our proposed approach allows testing of the underlying socio-economic and environmental drivers and their interaction in real environmental systems.

Key words: Systems dynamics modelling, Choice experiments, Integrated ecologicaleconomic modelling, Single Farm Payment, Habitat succession, Vegetation dynamics, Grouse, Land management, Uplands. 


\section{Introduction}

An overarching aim of land use change modelling in environmental research is firstly to understand how the spatial and temporal patterns of land managers' behaviours shape agricultural or forest systems (Agrawal et al., 2002). Secondly, how this leads to diverse environmental impacts; e.g. on biodiversity conservation (Drechsler, et al. 2007), on water quality (Nainggolan et al., 2018) and on climate services (Zandersen, et al., 2016; Prestele et al., 2017). Furthermore, models might also be designed to inform policy debates by providing a framework to anticipate and test how land use patterns may change under different hypothetical future scenarios (e.g. Wolff et al, 2018; Tieskens et al., 2017). Several interesting approaches have emerged to address different aspects of such research questions. In this paper, we focus on two of these, dynamic systems models and in particular agent based simulation models (ABMs) (An, 2012) and statistically based approaches using choice models (CMs) (Train, 2009).

In most cases, both ABMs and CMs have been used independently to understand the rationale and implications of land-use decisions. Several key developments in the application of ABMs to model land-use patterns have emerged over a long period of time (see eg. Bousquet et al. 1998; Agrawal et al., 2002; Veldkamp and Verburg 2004; Huber et al., 2018). These contributions have addressed interactions among individuals to simulate land-use decisions of individual agents. For example, Barreteau and Bousquet (2000) used an ABM to understand the influence of existing social networks on the viability of an irrigated farming system in the Senegal River Valley. However, it is acknowledged that it is still challenging to move beyond hypothetical landscapes, and parameterize and validate the interactions needed to model real landscapes (Huber et al., 2018). Never the less, a few studies have attempted to develop more realistic systems (see eg. Evans and Kelley 2004; Tieskens et al., 2017) and accounting for the role of decisions of heterogonous agents in landuse changes (Huigen 2004). A similar line of land-use related contributions have sought to determine how new agricultural practices are adopted by a population of farmers to better understand diffusion of technology (Balmann 1997, Berger 2001, Polhill et al. 2001; Schreinemachers et al, 2011). 
Another research approach used to explain or predict land managers' decisions is choice experiment (CE) designed to parameterise choice models (CMs). These have been used to understand and predict farmers' land-use decisions under a variety of hypothetical scenarios using data based on individuals' responses collected using questionnaires. One such example is the study by Baltas and Korka (2001) that used a nested discrete choice model to analyse land-use allocation under risk. A number of choice modelling applications have investigated the determinants explaining farmers' participation in environmental programs that would eventually lead to changes in land-use (Cooper and Keim 1996, Vanslembrouck et al. 2002, Lynch et al. 2002, Shaikh et al 2007, Peterson et al. 2007, Vedel et al., 2015; Aslam et al., 2017). These studies have determined the probability of farmers' participation in hypothetical agricultural improvement programs and estimated their willingness to accept (WTA) compensation for participation in these programs.

The two approaches outlined above, therefore, have complementary advantages for advancing how we integrate and model coupled social-ecological systems. The ABM has the advantage of being a dynamic framework, incorporating feedback mechanisms that allow behaviour to be investigated in coupled systems. However, the specification of human behaviour and its interaction with the natural resource is often highly abstract and few models in the literature are parameterised or validated using real spatially specific data. On the other hand, CMs have been developed to parameterise behavioural models and capture heterogeneity between agent types (Boxall and Adamowicz 2000, Milon and Scrogin 2006; Train, 2016). However, CEs have usually not been developed to analyse emergent system properties as agent. They are commonly assumed to be acting independently (perhaps with the exception of social interaction models e.g. Brock and Durlauf (2006)) and the dynamic environmental feedbacks are usually ignored. CMs do, however, have the potential to provide a theoretical and empirical foundation for the link between changing environments and the consequential responses of land managers. The combination of these two approaches to achieve a dynamically integrated model with empirically estimated behavioural rules, will, therefore, offer an advancement to modelling of land use dynamics. 
The combined use of ABMs and CMs appears to be rare in the literature on the environmental implications of land use decisions. One exception, is the study combining a catchment scale hydrological simulation model with a behavioural model of homeowners lawn watering behaviour to improve prediction of water demand (Conrad and Yates, 2018). However, there are studies that integrate the two approaches in other fields. Notably, in the field of transportation studies aiming to link individual road user behaviour wih aggregated traffic system dynamics (Dia 2002, Takama and Preston 2008). Takama and Preston investigate the effect of a road user charging scheme for visitors to the Upper Derwent Valley in the Peak District National Park. The authors use an ABM to incorporate an interaction term that accounts for congestion thereby enhancing the discrete choice model. Dia (2002), uses a discrete choice survey to obtain each driver's preferences and characteristics and each driver is then modelled as an agent. Agents interact with their environment and with other agents in the system by receiving and reacting to real-time traffic information. In the outdoor recreation context, Hunt, Kushneriuk and Lester (2007) developed a landscape fisheries model by using information from a revealed preference choice model and agent based models. Revealed preference data from each angler's trip and data on available fishing sites were used to parameterise an ABM for recreational fishing in Northern Ontario.

Building on the previous work, we propose an integrated ABM and CM by using a choice experiment to parameterise land managers behaviour in an agent based simulation model. We apply this approach in the upland ecosystems of the United Kingdom where land management is dominated by sheep and game bird production. To characterise agent behaviour we conduct a choice experiment with land managers in the Peak District National Park. The choice experiment was designed to reveal preferences for alternative production strategies under alternative scenarios of future change and to investigate the dependence of such choices on the changing environmental characteristics across the individuals' land management units. The choice data forms the basis for a behavioural model, which is integrated with a habitat succession model, to form an integrated model of landscape habitat dynamics. The integrated model allows us to evaluate future changes in land use and the way these changes impact the environment under different environmental and policy scenarios. The data stems from an earlier study by Chapman et al. (2009). However in this study 
we take the analysis further to improve understaning of the underlying drivers of the dynamics of the joint production system. Furthermore, we illustarte how the coupled model can be used to analyse potential impacts of agri-environmental policy reforms. We illustrate this by showing future projections of landscape changes related to hypothetical changes to the level of the current EU agricultural subsidies. This scheme is also known as the single farm payment (SFP), which is an area-based payment. The payment schemes are currently being revised (COM, 2017) and it is therefore interesting to understand the impacts of proposed changes.

\section{Methodology and Data}

\section{The study site}

The Peak District National park was established in 1951 and was the UK's first National Park. Its central location within easy reach of approximately $48 \%$ of England's population makes it one of the world's most visited national parks, with over 22 million visitor days a year (Peak District National Park, 2004). In addition to visitors, 38,000 people live within the park boundaries (Office for National Statistics, 2003) and $12 \%$ of them are employed in agriculture. However, agriculture is financially marginal, most farmers rely on government subsidies and 93\% of the national park is designated as a "Less Favoured Area" (European Commission Directive 75/268) (Dougill et al, 2006).

This study focused on the Dark Peak area in the north of the national park. The Dark Peak covers more than half of the national park, is predominantly on acidic peat soils over millstone grit and supports over 17,000 hectares of heather moorland and almost 16,000 hectares of blanket bog (Sustainable Uplands \& Moors for the Future, 2007) (Figure 1). Both of these habitats are recognized as internationally important. Both heather moorland and blanket bog are recognised as key biodiversity habitats (UK Biodiversity steering group, 1995), have been designated as Sites of Special Scientific Interest (SSSI) (English Nature, 2003) and are listed in the EU's Habitats Directive (92/43/EEC) as requiring special conservation measures as Special Areas of 
Conservation (SAC) and Special Protection Areas (SPA). Extensive sheep farming and grouse (Lagopus lagopus scoticus) moor management form the dominant land uses.

\section{FIGURE 1}

Sheep production has traditionally been subsidized by the European Union's Common Agricultural Policy (CAP), while grouse production has not. However, proposed changes to the single farm payment, SFP, scheme may shift the incentives to managing different types of production systems (COM, 2017). The key habitat management tool for grouse moors is rotational burning of heather to provide a mosaic of different age heather stands to maximise territories for grouse (Watson and Miller, 1976).

\section{Conceptual Model Overview}

We describe the upland system as a joint production system of sheep and grouse in which the farmer chooses stocking density throughout the year, whether or not to burn and the burning schedule. We focused on sheep and grouse as they have historically been, and still is, important for both the upland economy and the characteristic upland vegetation and landscape. By choosing the stocking densities and burning schedule the farmer impacts the costs of the production system as they arise from maintenance of the sheep flock, in particular over wintering, and the labour costs involved in heather moorland management. We refer to the combination of summer and winter sheep stocking density and the burning schedule as the "moorland management regime”, and the individual management characteristics (e.g. summer grazing density) as the management attributes. It is through the choice of moorland management regime that farmers impact their own livelihood, the broader upland economy and the upland environment, both the vegetation itself and other environmental variables such as water quality, carbon storage, biodiversity etc. The interdependence between the sheep and grouse relates to the abundance of the preferred habitat of sheep relative to grouse, which in turn is partially determined by the choice of management regime. 
The aim is to model the choices that farmers make both under current conditions and under hypothetical changes to the current situation to identify the preferable management regimes, from a farmers point of view, under varying environmental and economic conditions. It is important to note that we do not assume that farmers aim to maximise production or income from their land, we merely characterise the importance of environmental and economic factors for variation in land management choices across the landscape. In other words, we test whether we can estimate an attractiveness (or 'utility' using economic language) function of land management regimes by a combination of variables defining the moorland management regime, the environmental conditions of the land and the socio-economic conditions of the farmer. If actual and hypothetical choices are described well by the estimated model, this will help to understand better the spatial variation in management choices across the uplands and across upland farmers.

In this study, we test four basic hypotheses/relationships: (i) Land managers will display their relative preference for grouse production by choosing land management regimes favouring diverse heather age distributions; (ii) optimal stocking density and optimal burning regime (as perceived by the land managers) will vary across the landscape reflecting the variation in the carrying capacity for sheep and grouse and the land manager's desire to keep management costs low by reducing the number of wintering sheep and the area of burning; (iii) the extent to which management choices will vary with socio-economic characteristics of the land manager and the condition under which the land is managed, i.e. ownership or tenancy agreements; (iv) the robustness of the perceived optimal moorland management to changes in the level of the single farm payment, SFP.

In the model, land managers choose the favoured management regime given the characteristics of the plot of land. This results in a change in vegetation cover (of predominantly heather and grass), which in turn changes the perceived optimal strategy of the land manager. We investigate the dynamics of the coupled system of land management choices and habitat response. We compare scenarios by testing the differences between simulation outputs when changing amount of the single farm payment. Changing the mean temperature uniformly across the landscape simulates the impacts that climate change may have. 


\section{Data}

\section{Data collected to characterise the land managers' behaviour}

Face-to-face interviews were carried out with land managers in the Dark Peak area in 2006 and 2007. Potential respondents were identified using two methods. An initial contact list was generated from meetings with key stakeholders in the Peak District National Park. This allowed the interviews to be targeted only to land managers within the Dark Peak area and reduced the number of redundant contacts. Additional respondents were then identified using the snowball method (Bailey, 1982) where those taking part were then asked to identify others. It is important to note that land managers are often responsible for managing several areas with different management regimes. Therefore, each contact was asked separately about land management on all the different "land management units" under their control. We obtained complete observations of environmental and behavioural data for a total of 71 individual management units, representing $40 \%$ of the Dark Peak area. This was accomplished in 25 face-to-face-interviews.

Data were collected during the interviews using a standardised questionnaire based on both structured open-ended and closed-format questions. The questionnaire was piloted with key stakeholders before being used with respondents.

The first part of the questionnaire focused on identifying the type of land ownership (private versus tenancy) and the dominant land management activity carried out by the respondent (grouse moor management versus sheep farming). The extent of the land they managed was also identified using Ordnance Survey maps. Land was categorised into unique management units, reflecting heather moorland, rough grazing and improved pasture and the geographical boundaries between management units were recorded. The second part of the questionnaire was carried out for each of the identified management units and used a choice card for respondents to characterise their management. Respondents were first asked to characterise their current management strategies according to the variables on the card (Table 1) and this was recorded in the questionnaire. From this baseline respondents were then asked how their management would change under different hypothetical scenarios. In this paper 
we focus on the scenario related to changes in the single farm payment. In this scenario we asked land managers 'What if the current business environment stayed the same but the payments you currently receive from the single farm subsidy scheme changed so that you received $£ X$ per hectare, would your management change?' $X$ was drawn randomly from the following set: $10,20,30,40$, and 60 . The number of repetitions (variations in $\mathrm{X}$ ) of this experiment varied between interviews, depending on the number of management units, to limit the total amount of time spent on the questionnaire by each respondent. The maximum number of repetitions was four and the minimum two. This resulted in a total data set of 200 observations (Table 1).

\section{TABLE 1}

Data used for the habitat succession model.

Spatially-referenced environmental data used in the habitat succession model is specified in Table 2 and model formulation is outlined in the following section.

\section{TABLE 2}

\section{Model formulation and parameterisation}

The model consists of two integrated components, the behavioural model and the habitat succession model. In this section, both components are described individually and then their integration and joint simulation is outlined.

\section{Behavioural model}

The underlying premise of the models we set up is that land managers choose a land management regime to maximise the utility from the joint production of grouse and sheep.

We use a random utility approach (Train, 2003) to model land managers choices between alternative management regimes. This assumes, that a land manager chooses a management regime $j$ (defined as a combination of management attributes) in an 
area from the set of possible regimes $J$ with the highest expected utility from the chosen management regime. A general representative utility function of management regime $j$ chosen by land manager $n$, is specified as $v_{n j}$. The utility function includes (1) regime characteristics, $x_{n j}$, (2) environmental characteristics, $Z_{n}$, independent of the land management choices and (3) policy environment conditions, $s_{n}$, that are also independent of the choices the land manager makes. The expected utility that individual $n$ gains from land management regime $j$ is, therefore, comprised of a deterministic component $\left(v_{n j}\right)$ and a random error component $\left(\varepsilon_{n j}\right)$ specified as:

$U_{n j}=v_{n j}+\varepsilon_{n j}$

where $\quad v_{n j}=\boldsymbol{\beta}_{1}{ }^{\prime} \mathbf{x}_{n j}+\boldsymbol{\beta}_{2}{ }^{\prime} \mathbf{x}_{n j} \mathbf{z}_{n}+\boldsymbol{\beta}_{3}{ }^{\prime} \mathbf{x}_{n j} \mathbf{S}_{n} \cdot \boldsymbol{\beta}_{1}$ is a preference parameter vector representing the importance of individual regime characteristics in land managers choices (ie. parameters measuring preference for stocking density and heather diversity), $\boldsymbol{\beta}_{2}$ is the preference parameter vector accounting for variation across varying environmental conditions, and $\boldsymbol{\beta}_{3}$ accounts for the variation in preference parameters with varying policy environments. The error component $\varepsilon_{n j}$ is independently and identically distributed (iid) and follows a Type 1 extreme value distribution (Train, 2003).

The probability that individual $n$ chooses regime $i$ can be derived given the parameter vectors $\beta_{1}, \beta_{2}, \beta_{3}$ using the multinomial logit model (MNL) specified as follows:

$$
\operatorname{Pr}_{n i}=\frac{\exp \left(v_{n i}\right)}{\sum_{j \in J} \exp \left(v_{n j}\right)}
$$

The parameters are derived using maximum likelihood estimation using the Gauss software, version 6.0. There is no information on the subset of land management regimes considered by the land manager on each plot of land. However, all alternatives are available to the land managers and the choice set is modelled as the chosen regime and a random selection of alternatives. The advantage of this approach is the reduction in computing effort. More importantly, this approach has been shown 
to generate very similar relative parameter estimates to those obtained when the estimation choice set is the same as the total potential choice sets (Parsons and Kealy, 1992; Termansen et al., 2004). We test for parameter stability with increasing size of the choice set to ensure that the selected model specification is not dependent on the arbitrary choice of number of alternative regimes considered.

\section{Habitat Dynamics Model}

The habitat model is a spatially explicit grid based model of the dynamics of the moorland vegetation cover. Space is represented as a $100 \times 100 \mathrm{~m}$ grid aligned to the Ordnance Survey British National Grid. The state of each grid cell is given by the cover of dwarf shrubs (predominantly heather Calluna vulgaris), bracken Pteridium aquilinum, graminoids (grasses, sedges and rushes) and bare peat. Dwarf shrubs are further divided into five growth phases based on the number of years since the last burn. The phases are newly burnt (0-2 years), pioneer (3-5 years), building (6-15 years), mature (16-25 years) and degenerate (26+ years) (Barclay-Estrup and Gimingham 1969). It is assumed that dwarf shrubs will remain in the degenerate stage indefinitely if it is not burned, and that cells colonised by dwarf shrubs enter the pioneer stage. Aging and the choice of burning regime determine the diversity of the dwarf shrub habitat, represented in the model by the Shannon-Weaver diversity index (Shannon, 1948).

The habitat dynamics is based on the model developed by Chapman et al. (2010). Changes in habitat cover are determined by competition between dwarf shrubs, bracken and graminoids. This is mediated by grazing pressure, dwarf shrub age distribution (determined by burning) and environmental gradients. We follow the work from Palmer et al. (2004) and assume that provided grazing pressure is sufficiently low, and the environment sufficiently suitable, dwarf shrubs will dominate graminoids and bracken, and will increase in cover. We, however, modify Palmer et al's model for changes in dwarf shrub cover as a function of the proportion of annual productivity eaten by grazing sheep (the utilisation rate). Modifications include accounting for variations in habitat quality, the composition of competing vegetation and the dwarf growth phase following the principles described in Chapman et al. (2010). Habitat quality is determined by temperature, rainfall, topography and 
bedrock type. For a full specification of the vegetation dynamics refer to Chapman et al. (2010).

Managers decide how many sheep to release onto each management unit during summer and winter, but these sheep are free to move through the unit and so stocking density is therefore not uniformly distributed. We assume that sheep are distributed across the cells in proportion to the cover of their preferred forage (graminoids, including those growing within other vegetation types, following Armstrong et al. 1997a,b). Once stock density through the year has been calculated, the grazing utilisation rate of dwarf shrubs is estimated using the Hill Grazing Management Model (HGMM; Armstrong et al. 1997a,b). The HGMM is a very complex model from which we are only interested in determining of sheep grazing pressure. We have, therefore, produced a HGMM-emulator by running the model for selected variations in inputs (summer and winter stocking densities, proportions of dwarf shrub in each growth phase and temperature) and modelled the resulting grazing pressure using multiple regression. Chapman et al. (2010) gives full detail of this procedure and the results obtained.

Managed burning in each management unit is implemented in each year with a probability calculated as the inverse of the burning frequency given in the land management strategy. Burning affects entire grid cells, and we assume that cells are eligible for burning if the area of dwarf shrubs exceeds a threshold of 0.3 ha, equivalent to the average size of a burning plot. The land management strategy gives the proportion of the eligible cells that are burnt each time burning occurs. These are selected as the oldest of the eligible cells. We assume that the burn is controlled and at a low temperature so that it simply resets the age of the dwarf shrub to zero. Negative impacts on dwarf shrub regeneration of high temperature burns have not been included in the model.

\section{Simulation procedure}

Management decisions are made in each year with a probability of 0.2 , i.e. every 5 years on average. Decisions are made by selecting a strategy from the observed set with a probability in proportion to the values of $\exp \left(v_{n j}\right)$ (Equation 2) for all observed strategies, as determined by the choice model. 
Stocking densities are distributed in each land management unit according to habitat preference of sheep and the chosen burning events are simulated by updating the state of the burned patches.

Models are initiated with the observed management strategies and vegetation cover and run to equilibrium over a 500 year transient. Outputs are then collected over the next 500 years and include the frequencies with which each management unit chooses each observed strategy. These data are used to calculate the mean values of the management strategies, such as the stocking densities, and the proportion cover of each vegetation type across the simulated landscapes.

\section{Analysis of simulated data}

Ten replicate simulations are run to establish equilibrium conditions for each combination of single farm payment level and degree of climate change. Climate change is modelled as a uniform increase in temperature by 0 to 3 degrees Celsius (in $0.5{ }^{\circ} \mathrm{C}$ steps). Generalised linear models are used to analyse the components of the mean strategies outputted for each combination.

\section{Results}

\section{Behavioural model specification}

The selected model shows that farmers' utility from land management is dependent on stocking density, heather diversity, elevation, costs associated with sheep farming and burning and subsidy received (Table 3). The analysis did not show any evidence of dependence of the tested socio-economic characteristics of the land manager. We define low SFP as payment below $£ 20 /$ ha and high SFP as payments above $£ 60 / h a$, as these specifications had the best statistical fit to the observed data. Heather dominated land is defined as dwarf shrub occupying more than $50 \%$ of the management unit. This threshold was also estimated based on statistical fit.

TABLE 3 
The probability of choosing a land management regime with a high stocking density increase with temperature reflecting the higher stocking densities in the valleys compared to the hilltops $\left(\beta_{2}^{2}>0, P<0.05\right)$. This effect is augmented by a background level propensity to choose management regimes with low sheep stocking densities $\left(\beta_{1}^{1}<0, P<0.05\right)$. It would be expected that land managers would attempt to avoid land management options that lead to high costs associated with wintering costs, however, we do not find this effect to be significant. For scenarios representing a reduction in the SFP, the probability of choosing management regimes with high stocking densities is reduced $\left(\beta_{3}^{1}<0, P<0.05\right)$. Land managers display a preference for land management regimes with higher dwarf shrub diversity on dwarf shrub dominated land $\left(\beta_{2}^{1}>0, P<0.05\right)$. High burning costs regimes are avoided, other aspect being equal $\left(\beta_{1}^{2}<0, P<0.05\right)$. For high SFP scenarios the probability of choosing management regimes generating high dwarf diversity increases $\left(\beta_{3}^{2}>0, P<\right.$ $0.05)$.

Relative parameter stability to choice set specification show that this aspect of model estimation has little bearing on the final formulation (Figure 2). We illustrate this for two sets of relative parameters: (i) the parameter capturing the preference for heather diversity on heather dominated land $\left(\beta_{2}^{1}\right)$ relative to the parameter capturing the farmers' propensity to avoid burning costs $\left(\beta_{1}^{2}\right)$; (ii) the parameter capturing the change in preference for stocking density under a reduction in the single farm payment to less than $£ 20 / \mathrm{ha}\left(\beta_{3}^{1}\right)$ relative to the parameter capturing the disutility from occurring away wintering costs $\left(\beta_{1}^{3}\right)$.

\section{FIGURE 2}

The analysis shows that when the size of the choice set is below approximately 50 the relative parameter values are not stable, but results seem to be unaffected by the size of the choice set for larger choice sets. The results reported (Table 3) and used for further analysis are the results for a model estimated with 100 alternatives. 


\section{Predicted impact on stocking densities}

The generalised linear model fitted to simulated summer stocking densities $\left(R^{2}\right.$ adj $\left.=0.816\right)$ showed significant effects of the size of the area of the management unit $(t=2.008, P=0.045)$, current mean temperature $(t=72.30, P<0.001)$, degree of warming $(t=218.0, P<0.001)$ and single farm payment $(P<0.001$ for both factor levels) (Table 4). Farmers apply on average a higher summer stocking density to larger management units with higher temperatures (i.e. areas at lower elevation or with more severe climate change). Low levels of single farm payment are predicted to lead to a decrease in stocking density compared to the current levels (Figure 3a). High levels of the payment is also predicted to lead to reduced stocking densities compared to the current payment levels $(P<0.001)$, however this effect is only apparent when analysing the individual management unit data. The landscape mean over the 10 simulations is not different to the mean outcome under the current payments (Figure 3a). The simulations suggest that increasing temperature under climate change outweighs the differences resulting from changes in the single farm payment. However, as the management regimes do not include options above a stocking density of 3 sheep/ha, this prediction could be a result of this selection of choice set design (Figure 3a). Similar results hold for variation in the winter stocking densities, however, the effect of the size of management area is not significant ( $t=$ 0.787, $P=0.432$ ). Furthermore, the mean effect from the 10 simulations of different levels of the single farm payment also suggests that only the low payment levels generate a significantly lower winter stocking density for some warming scenarios (Figure $3 \mathrm{~b}$ ).

TABLE 4

FIGURE 3

\section{Predicted impact on burning activities}

Simulated proportions of time employing grouse moor management (strategies involving some burning) were analysed using a GLM with binomial error structure corrected for overdispersion $\left(\mathrm{R}^{2}\right.$ adj $\left.=0.405\right)$. Under the current climate, managers 
mostly express a clear preference for either grouse moor management or sheep production (Figure 4a-c). However, a reduced preference for grouse is seen at medium levels of SFP $(t=-31.65, P<0.001)$ and for large management units $(t=$ 4.083, $P<0.001)$ at currently high temperatures/low elevations $(t=-23.41, P<$ 0.001). As the climate gets warmer, the preference grouse management also declines $(t=-86.63, P<0.001)$ and we see a shift away from managed burning towards grazing (Figure 4a-c). However, there is only a small impact on the burning practices of management units that still engage in burning (Figure 4d).

TABLE 4

FIGURE 4

\section{Predicted impact on land cover}

The results on vegetation cover reflect both the natural habitat dynamics and the management responses. At current temperatures the proportions of dwarf shrub are inversely related to the summer grazing pressure determined by the SFP level, while the opposite is true for graminoids and bare peat, both of which are favoured by higher grazing (Figure 5a-c). Bracken is not eaten by sheep so is relatively unaffected by grazing (Figure 5d). However its habitat quality is strongly constrained by a need for high temperature and so warmer temperatures allow it to move up the hill and increase in cover. Dwarf shrub quality peaks at moderate temperatures, so in theory warming should increase cover in the coldest sites but decrease it in the warmest. However, warmer temperatures also bring higher grazing pressure in the model, which offsets any gains in cover in the colder sites. Graminoids and bare peat both favour colder temperatures, so a slight warming reduces their cover. However, as the temperature increases further and dwarf shrubs are lost to overgrazing then graminoids and bare peat expand in cover. At warmer temperatures, management converges away from burning for grouse moor and towards sheep production and so the responses of vegetation to variation in the SFP become smaller.

\section{FIGURE 5}




\section{Discussion and conclusion}

Much work has been devoted to anticipate the affects of alternative reforms of the European agricultural policy schemes. Previous modelling studies from the UK uplands have shown a general trend towards extensification in the uplands as a result of decoupling production and subsidy payments with the introduction of the single farm payment (Oglethorpe 2005, Matthews et al. 2006, Svetlana et al 2008). Extensification includes a reduction in sheep and cattle densities and also a reduction in the average per hectare use of inorganic fertilizers, the movement to lower stocking densities and shifts away from traditional suckler beef systems to sheep systems. The substitution of cattle systems with sheep is thought to be due to the lower fixed costs (i.e. operations and contractor costs) associated with sheep systems (Matthews et al 2006). The results of this study suggests, that even when subsidy payments are decoupled from agricultural production, the level of payments is likely to impact the priorities in land management, although this should not be the case if farmers were strictly profit maximising agents. Our analysis suggests that there are two competing explanations for the nature of the impact on land management of changes to the level of the single farm payments. These two competing explanations could broadly be defined as the payment scheme's impact on: (i) the propensity to diversify to make up for lost earnings, and (ii) the economic capacity of land owners to maintain a given level of land management activity. Our analysis shows that a reduction in the single farm payment leads to a reduction in stocking density and an increase in burning activities. This result can be interpreted by combining the insights from the behavioural model and the vegetation dynamics model. The reduction in the single farm payment reduces the stocking density. This mainly results from the proportion of farmers giving up sheep production under this scenario. In turn, the reduced sheep density promotes dwarf shrub regeneration, and this leads to an increase in the utility from choosing a grouse production management strategy. Overall, the results suggest that reducing the single farm payment introduces a shift in land management priorities to a regime less dominated by sheep grazing and more dominated by grouse shooting. As the single farm payment is independent of the amount of production, this suggests that current management practices are not financially viable but maintained through the subsidy. An increase in the single farm payment also results in a shift away from 
sheep grazing towards grouse moor management. This suggests that under more favourable financial circumstances, expensive but valued management regimes become relatively more attractive and land managers chose to invest more in the generation of habitats for grouse production. Again this suggest that land managers in the upland are motivated not purely by financial objectives but still are impacted by the financial constraints under which they carry out their business operations. Taken together, these results suggest that "other factors" rather than just profit contribute to farmers' utility, and therefore also important in determining land management decisions.

In terms of understanding these other factors, there are at least two key fields that provide conceptual and empirical insights. The first come from behavioural studies, considering in particular, why some farmers voluntarily sign up to some policies and not others (Potter and Gasson, 1988; Brotherton, 1989; Brotherton, 1991; Wilson 1997; Zandersen, et al. 2016; Aslam et al. 2017). The second field is based in rural sociology and seeks to account for the persistence of "middle-range" family farms that are too big to be a "hobby" farm but too small to be economically viable on their own. In this case, family structure and employment mobility are seen as important factors that drive the decision to stay in farming (Munton and Marsden, 1991). In our study, we have not been able to quantify socio-economic characteristics favouring particular types of behaviours. However, the more qualitative studies from this study area, do give evidence of different land management groupings impacting on land management choices (Dougill et al., 2006). External industry factors, along the supply and demand chain may also be important factors of land management behaviour, e.g. work in Canada has showed that structural factors, such as the nature of the food processing industry (Fraser, 2006) and land tenure (Fraser, 2004) all have significant influences on the types of crops a farmer plants and the extent to which they engage in soil conservation practices.

This study has also investigated the extent to which the interaction between the decision-making in various habitats and the vegetation dynamics are sensitive to climate change. The model predicts significant changes to both land management behaviour and vegetation cover. The system is predicted to shift towards a grazingbased system, where stocking densities increase, dwarf cover declines resulting in a 
reduction in burning activities. It should however be noted, that in the vegetation models, temperature increases that pushed individual cells above the observed maximum temperature were treated as having the same effect as raising temperature to the observed maximum. This was because nonlinear relationships fitted to local data could not be extrapolated to higher temperatures. This means that bracken may in reality continue to increase in dominance at high temperatures rather than reach an asymptote. Furthermore, the temperature dependency in the behavioural model is represented by a linear relationship, this may have resulted in unrealistic predictions of climate effects for lower elevation areas. Management decisions converge at high temperatures but this could be due to the fact that high stocking density options are not present in the choice set. This means that the increase in stocking densities might be even more severe that the simulated results indicate.

The approach illustrated in this paper could potentially be improved to include more elaborated decision models given replications of the types of data we use here to a larger sample size. The relatively recent developments in discrete choice modelling to capture heterogeneity in preferences between individuals or groups of individuals, by application of the mixed logit model (Train, 2003) or the latent class models (Boxall and Adamowicz, 2000), offers interesting extensions of the approach we have proposed here. Furthermore, new developments in choice modelling over the last decade could potentially be used to model complex decision-making processes. This could potentially be achieved using hybrid choice models (Ben-Akiva et al., 2002; Hess and Beharry-Borg, 2012).

The present paper has however made a contribution to the way in which discrete choice models of land use behaviour can be considered in an integrated model. Our approach allows the simulation of choices in response to the environmental consequences of past actions, a factor usually ignored in studies using choice modelling. Furthermore, the behavioural rules are revealed through empirical data rather than dictated through expert opinions, derived from the literature or simply assumed. This allows the research to test the statistical significance of various determinants of choice. Moreover, the behavioural choice model generates probabilities of alternative behaviours that makes it ideally suited for integration with simulation models. 


\section{Acknowledgements}

The paper has been funded through the Rural Economy and Land Use (RELU) programme, co-sponsored by Defra and SEERAD (project RES-224-25-0088). The authors would like to thank the farmers, landowners and gamekeepers of the Peak District National Park who gave their time to take part in the questionnaires. Furthermore, the paper has benefited from support from the PREAR project (No 652615) granted under the FACCE SURPLUS ERA-NET Cofund. 


\section{References}

An, J. (2012). Modeling human decisions in coupled human and natural systems: Review of agent-based models. Ecological Modelling, 229:25-36

Agarwal, C., Green, G.M., Grove, J.M., Evans, T.P., Schweik, C.M. (2002).

A Review and Assessment of Land-use Change Models: Dynamics of Space, Time and Human Choice. US Department of Agriculture, Forest Service Northeastern Research Station Newton Square, PA

Armstrong, H.M., Gordon, I.J., Grant, S.A., Hutchings, N.J., Milne, J.A. and Sibbald, A.R. (1997a) A model of the grazing of hill vegetation by the sheep in the UK. I. The prediction of vegetation biomass. Journal of Applied Ecology, 34, 166-185.

Armstrong, H.M., Gordon, I.J., Hutchings, N.J., Illuis, A.W., Milne, J.A. and Sibbald, A.R. (1997b) A model of the grazing of hill vegetation by sheep in the UK. II. The prediction of offtake by sheep. Journal of Applied Ecology, 34, 186-207.

Aslam, U; Termansen, M; Fleskens, L (2017). Investigating farmers’ preferences for alternative PES schemes to promote carbon sequestration in UK agroecosystems. Ecosystem Services, 27(A): 103-112.

Bailey KD. 1982. Methods of Social Research. New York: Free Press.

Balmann, A. (1997). Farm-based modelling of regional structural change. European Review of Agricultural Economics, 25 (1), 85-108.

Baltas, N.C., and Korka, O. (2002). Modelling farmers’ land use decisions. Applied Economics Letters, 9, 453-457. 
Barclay-Estrup, P. \& Gimingham, C.H. (1969) Description and interpretation of cyclical processes in a heath community. I. Vegetational change in relation to the Calluna cycle. Journal of Ecology, 57, 737-758.

Barreteau, O., Bousquet, F., 2000. SHADOC: a multi-agent model to tackle viability of irrigated systems. Annals of Operations Research, 94, 139-162.

Ben-Akiva, M., McFadden, D., Train, K., Walker, J., Bhat, C., Bierlaire, M., Bolduc, D., Boersch-Supan, A., Brownstone, D., Bunch, D.S., Daly, A., De Palma, A., Gopinath, D., Karlstrom, A., Munizaga, M.A., 2002. Hybrid choice models: progress and challenges. Mark. Lett. 13 (3), 163-175.

Berger, T., 2001. Agent-based spatial models applied to agriculture: a simulation tool for technology diffusion. Resource use changes and policy analysis. Agricultural Economics, 25(2-3), 245-260.

Boxall, P. \& Adamowicz, W. (2002), Understanding heterogeneous preferences in random utility models: A latent class approach, Environmental and Resource Economics, 23, 421-446

Bousquet, F., Bakam, I., Proton, H., Le Page, C., 1998. Cormas: commonpool resources and multi agent systems. Lecture Notes in Artificial Intelligence, 1416, 826837.

Brock, W.A. and Durlauf, S.N. (2006). Multinomial Choice with Social Interactions in Blume, L.E. and Durlauf S.N. (eds) The Economy as an Evolving Complex System, III. Current Perspectives and Future Directions. Santa fee institute studies in the sciences of complexity.

Brotherton, I. (1989) Farmer participation in voluntary land diversion schemes: Some observations from theory. Journal of Rural Studies, 5, 299-304.

Brotherton, I. (1991) What limits participation in ESAs? Journal of Environmental Management, 32, 241-249. 
Chapman, D., Termansen, M., Quinn, C.H., Jin, N., Bonn, A., Cornell, S. Fraser, E.D.G., Hubacek, K., Kunin, W. and Reed, M. (2009). Modelling the coupled dynamics of moorland management and vegetation in the UK uplands. Journal of Applied Ecology, 46, 278-288.

Chapman, S.S., Bonn, A. Kunin, W.E. and Cornell, S. J. (2010). Random Forest characterization of upland vegetation and management burning from aerial imagery. Journal of Biogeography, 37:37-46.

COM (2017). The future of food and farming. Brussels.29.11.2017. COM(2017) 713 final.

Conrad, S.A.; Yates, D. (2018). Coupling stated preferences with a hydrological water resource model to inform water policies for residential areas in the Okanagan Basin, Canada. Journal of Hydrology, 564:846-858.

Cooper, J. C, Keim, R. W. (1996) Incentive Payments to Encourage Farmer Adoption of Water Quality Protection Practices. American Journal of Agricultural Economics, 78(1), 54-64.

Dia, H. (2001). An agent-based approach to modelling driver route choice behaviour under the influence of real-time information. Transportation Research. Part C, 10, 331-349.

Dougill, A.J., Fraser, E.D.G., Holden, J., Hubacek, K., Prell, C., Reed, M.S., Stagl, S. \& Stringer, L.C. (2006). Learning from doing participatory rural research: lessons from the Peak District National Park. Journal of Agricultural Economics, 57, 259275.

Drechsler, M., Johst, K; C. Ohl, C., Wätzold, W. (2007) Designing cost-effective payments for conservation measures to generate spatiotemporal habitat heterogeneity Conservation Biology, 21:1475-1486. 
English Nature, 2003. England's Best Wildlife and Geological Sites; The Condition of SSSIs in England in 2003. Peterborough: English Nature.

Evans, T.P., Kelley, H., 2004. Multi-scale analysis of a household level agent-based model of land cover change. Journal of Environmental Management, 72, 57-72.

Fraser, E. D. (2006) Crop diversification and trade liberalization: Linking global trade and local management through a regional case study. Agriculture and Human Values, 23, 271-281.

Fraser, E.D.G. (2004) Land tenure and agricultural management: Soil conservation on rented and owned fields in southwest British Columbia. Agriculture and Human Values, 21, 73-79.

Herriges, J.A. and D.J. Phaneuf, (2002) Inducing patterns of correlation and substitution in repeated logit models of recreation demand, American Journal of Agricultural Economics, 84, 1076-1090.

Hess, S. and Beharry-Borg, N. (2012). Accounting for Latent Attitudes in Willingness-to-Pay Studies: The Case of Coastal Water Quality Improvements in Tobago. Environmental and Resource Economics 52: 109-131.

Huber, R.; Bakker, M.; Balmann, A.; Berger, T.; Bithell, M.; Brown, C.; GretRegamey, A.; Xiong, H.; Le, Q.B.; Mack, G.; Meyfroidt, P.; Millington, J; Muller, B.; Polhill, J.G.; Sun, Z.; Seidl, R.; Troost, C.; Finger, R. (2018). Agricultural Systems, $167: 143-160$.

Huigen, M.G.A., 2004. First principles of the Mameluke multi-actor modelling framework for land use change, illustrated with a Philippine case study. Journal of Environmental Management, 72, 5-21.

Hunt, L.M., Kushneriuk, R. and Lester, N. (2007). Linking agent-based and choice models to study outdoor recreation behaviours: a case of the Landscape Fisheries 
Model in northern Ontario, Canada. Forest, Snow and Landscape Research, 81, 163174.

Lynch, L., Hardie, I., and Parker, D. (2002). Analyzing Agricultural Landowners' Willingness to Install Streamside Buffers. Working Paper from The Department of Agricultural and Resource Economics, The University of Maryland, College Park.

Matthews, K.B., Wright, I.A., Buchan, K., Davies D.A. and Schwarz, G. (2006). Assessing the options for upland livestock systems under CAP reform: Developing and applying a livestock systems model within whole-farm systems analysis, Agricultural Systems, 90, 32-61.

Milon, J.W. and Scrogin, D. (2006), Latent preferences and valuation of wetland ecosystem restoration, Ecological Economics, 56, 162-175.

Munton, R. and Marsden, T. (1991) Dualism or diversity in family farming? Patterns of occupancy change in British agriculture. Geoforum, 22, 105-117.

Nainggolan, D, Hasler, B, Andersen, HE, Gyldenkærne, S \& Termansen, M 2018, 'Water quality management and climate change mitigation: cost-effectiveness of joint implementation in the Baltic Sea region', Ecological Economics, vol. 144, pp. 12-26.

Office for National Statistics, 2003. Census 2001: CD Supplement to the National Report for England and Wales and Key Statistics for Local Authorities in England and Wales. London:Office for National Statistics.

Oglethorpe, D.R. (2005). Livestock production post CAP reform: implications for the environment; Animal Science, 81,189-192.

Parsons, G.R. and Kealy, M.J. (1992) Randomly Drawn Opportunity Sets in a Random Utility Model of Lake Recreation, Land Economics 68, 93-106.

Peak District National Park, 2004. State of the Park Report (update). http://www.peak district.org. 
Peterson, J.M., Fox, J.A., Leatherman J.C., Smith, C.M. Choice Experiments to Assess Farmers' Willingness to Participate in a Water Quality Trading Market. Kansas State University. Selected paper prepared for presentation at the American Agricultural Economics Association Annual Meeting, Portland, Oregon, July 29August 1, 2007.

Polhill, J.G., Gotts, N.M. and Law, A.N.R.. 2001. Imitative versus nonimitative strategies in a land-use simulation. Cybernetics and Systems, 32 (1), 285-307.

Potter, C. and Gasson, R. (1988) Farmer participation in voluntary land diversion schemes: Some predictions from a survey. Journal of Rural Studies, 4, 365-375.

Prestele, R., Arneth, A., Bondeau, A., de Noblet-Ducoudré, N., Pugh, T. A. M., Sitch, S., Stehfest, E., and Verburg, P. H. (2017). Current challenges of implementing anthropogenic land-use and land-cover change in models contributing to climate change assessments, Earth Systystem Dynamics, 8: 369-386.

Shaikh, S.L., Sun, L., van Kooten, G.C. (2005). Are Agricultural Values a Reliable Guide in Determining Landowners' Decisions to Create Forest Carbon Sinks? Canadian Journal of Agricultural Economics, 55, 97-114 .

Schreinemachers, P.; Berger, T. (2011). An agent-based simulation model of humanenvironment interactions in agricultural systems. Environmental Modelling and Software, 26(7):845-859.

Silvano, R.A.M., Silva, A.L., Ceron, M., and Begossi, A. 2008. Contributions of ethnobiology to the conservation of tropical rivers and streams. Aquatic conservation - Marine and freshwater ecosystems, 18(3): 241-260.

Sustainable Uplands and Moors for the Future (2007). Looking after moorland habitats. Sustainable Uplands Project. Research Note 14, School of Earth and Environment, University of Leeds, UK. 
Szvetlana, A., Hanley, N., Dallimer, M., Robertson, P., Gaston, K., Armsworth, P.R., (2008). Impacts of policy reform on sustainability of hill farming in U.K.by means of bio-economic modelling. Paper prepared for presentation at the 107th EAAE Seminar "Modelling of Agricultural and Rural Development Policies". Sevilla, Spain.

Takama, T., Preston, J., (2008). Forecasting the effects of road user charge by Stochastic agent-based modelling. Transportation Research: Part A, 42, 738-749.

Termansen, M., McClean, C.J. and H. Skov-Petersen, H. (2004) Recreational site choice modeling using high spatial resolution data, Environment and Planning A, 36, 1085-1099.

Tieskens, K.F., Shaw, B.J., Haer, T., Schulp, C.J.E. \& Verburg, P.H. (2017). Cultural landscapes of the future: using agent-based modeling to discuss and develop the use and management of the cultural landscape of South West Devon. Landscape Ecology, 32, 2113-2132.

Train, K. (2003) Discrete choice methods with simulation, Cambridge University Press.

Train, K. (2016). Mixed logit with a flexible mixing distribution. Journal of choice modelling, 19, 40-53.

UK Biodiversity Steering Group, 1995. The UK Steering Group Report - Volume II: Action Plans. London: HMSO.

Vanslembrouck, I., Huylenbroeck, G.V., and Verbeke, W. (2002). Determinants of the Willingness of Belgian Farmers to Participate in Agri-environmental Measures. Journal of Agricultural Economics, 53(3), 489-511.

Vedel, S.E., Jacobsen, J.B. and Thorsen, B.J. (2015), Contracts for afforestation and the role of monitoring for landowners' willingness to accept, Forest Policy and Economics, 51: 29-37. 
Veldkamp, A., Verburg, P.H. (2004). Modelling land use change and environmental impact. Journal of Environmental Management, 72, 1-3.

Watson A. \& Miller G.R., 1976. Grouse Management. Game and Wildlife Conservation Trust. Hampshire: Fordingbridge.

Willock, J., Deary, I.J., Mcgregor, M.M., Sutherland, A., Edward-Jones, G., Morgan, O., Dent, B., Grieve, R., Gibson, G. and Ausin, E. (1999). Farmers' Attitudes, Objectives, Behaviors, and Personality Traits: The Edinburgh Study of Decision Making on Farms. Journal of Vocational Behavior, 54, 5-36.

Wilson, G. A. (1997) Factors Influencing Farmer Participation in the Environmentally Sensitive Areas Scheme. Journal of Environmental Management, 50, 67-93.

Zandersen, M., Jørgensen, S.L., Nainggolan, D., Gyldenkærne, S., Winding, A., Greve, M.H. \& Termansen, M. (2016). Potential and economic efficiency of using reduced tillage to mitigate climate effects in Danish agriculture. Ecological Economics, 123: 14-22. 


\section{TABLES}

Table 1

Variable

Land Holding, LH
Management Unit, MU
Tenancy, T
Dominant land use
DOM
Grazing time, GT
Stocking Rate, SR
Stocking Density, SD
Burning Frequency, BF
Burning Proportion, BP
Shannon Diversity
Index, SH

Single Farm Payment, SFP

$\mathrm{SFP}_{\mathrm{L}}$

$\mathrm{SFP}_{\mathrm{M}}$

$\mathrm{SFP}_{\mathrm{H}}$

Temperature, Temp

Grass

Heather

$\mathrm{D}_{\mathrm{H}}$

Burning costs, BC Wintering costs, WC
Description

Source

Geographical mapping of individual land holdings.

Interviews

Geographical mapping of areas with uniform management Interviews strategy. Digitised in ArcGIS.

Owned by land manager, land manager tenant on the land, land Interviews manager employed.

Land predominantly used for grazing, land predominantly used for Interviews grouse shooting, Land predominantly used for other purpose.

The temporal extent of the grazing; no grazing, spring and summer, all year with $25 \%$ reduction in winter, all year.

Interviews

Choice card

Stocking Rate when sheep are grassing the land; no grazing, 0.5 sheep/ha, 1sheep/ha, 2 sheep/ha, 3 sheep/ha.

Average summer stocking density, calculated by combining GT and SR.

Frequency of burning in a management unit; every year, every other year, every third year, every fifth year, never.

Proportion burned when management unit is burned; 0.5\%, $10 \%$, $15 \%$ and $20 \%$

Shannon-Weaver's Diversity Index of dwarf shrubs age distribution. Calculated from each management option (combination of BF and BP) in a simple dwarf shrub succession model on a $100 \times 100$ grid of dwarf shrub.

Actual and hypothetical area payment independent of farming intensity; 0, 10, 20, 40, 60 £/ha

Dummy variable for SFP, $\mathrm{SFP}_{\mathrm{L}}=1$ if $\mathrm{SFP}<\mathrm{L}$, otherwise $\mathrm{SPF}_{\mathrm{L}}=$ 0

Dummy variable for SFP, $\mathrm{SFP}_{M}=1$ if $\mathrm{L}<\mathrm{SFP}<\mathrm{H}$, otherwise Derived $\mathrm{SPF}_{\mathrm{M}}=0$

Dummy variable for SFP, $\mathrm{SFP}_{\mathrm{H}}=1$ if $\mathrm{SFP}_{\mathrm{H}}>\mathrm{H}$, otherwise $\mathrm{SPF}_{\mathrm{H}}$ $=0$

Used as proxy for Elevation; to capture land carrying capacity.

Proportion of gramionoids (grasses) in each MU

Proportion of dwarf shrub in each MA

Dummy variable for Heather dominant MA; $D_{H}=1$ when Heather

$>0.5$, otherwise $\mathrm{D}_{\mathrm{H}}=0$.

Costs of burning measured as labour requirement per unit of land.

Costs of keeping sheep off the moors over winter.
Interviews

Choice card

Derived

Interviews

Choice card

Interviews

Choice card

Derived

Interviews

Derived

Derived

Met Office

weather

stations

LCM

LCM

Derived

Interviews

Interviews

${ }^{1}$ http://www.badc.nerc.ac.uk/data/ukmo-midas

Table 2

\section{Variables Description}

LCM

Slope

Aspect

Rainfall
Land Cover Map in 2005 grouped into dwarf shrubs, bracken, graminoid, bare peat and bare rock, $5 \times 5 \mathrm{~m}$ resolution.

Mean slope (degrees) derived from the NEXTmap Digital Elevation Model ( $5 \times 5 \mathrm{~m}$ resolution)

Aspect (north, south, east, west) derived from the NEXTmap Digital Elevation Model ( $5 \times 5 \mathrm{~m}$ resolution)

Mean annual rainfall, interpolated at $100 \times 100 \mathrm{~m}$ resolution.

\section{Source}

Chapman et al., 2010

NEXTmap $^{1}$

NEXTmap $^{1}$

Met Office weather 
Temperature Mean annual temperature, interpolated at $100 \times 100 \mathrm{~m}$ resolution.

Bedrock Bedrock classified as either sandstone or mixed.

Warming Additional degrees Celsius added to the mean annual temperature

${ }^{1}$ http://www/neodc.rl.ac.uk; ${ }^{2}$ http://www.badc.nerc.ac.uk/data/ukmo-midas;

${ }^{3}$ http://www.bgs.ac.uk/products/digitalmaps/home/html stations $^{2}$

Met Office weather stations $^{2}$

British Geological Survey bedrock map $^{3}$

Scenario assumption

Table 3

\begin{tabular}{lccc} 
Variable & Parameter & Estimate & t-statistics \\
\hline Stocking Density & $\beta_{1}^{1}$ & -3.828 & -2.86 \\
Socking Density $\times \mathrm{SFP}_{\mathrm{L}}$ & $\beta_{3}^{1}$ & -0.531 & -3.01 \\
Shannon Diversity Index $\times$ Heather $\cdot \mathrm{D}_{\mathrm{H}}$ & $\beta_{2}^{1}$ & 4.266 & 4.62 \\
Shannon Diversity Index $\times \mathrm{SFP}_{\mathrm{H}}$ & $\beta_{3}^{2}$ & 0.959 & 2.60 \\
Burning Costs & $\beta_{1}^{2}$ & -0.019 & -3.82 \\
Wintering Costs & $\beta_{1}^{3}$ & -0.015 & -1.27 \\
Stocking Density $\times$ Temperature & $\beta_{2}^{2}$ & 0.5356 & 3.05
\end{tabular}

Table 4

Summer stocking densities

Winter stocking densities

Variable

Estimates

t-statistics

Estimates

t-statistics

Intercept

$-1.862$

$-44.396$

79.922

0.183

17.192

$\mathrm{SFP}_{\mathrm{H}}$

0.439

58.961

0.0573

40.985

Warming

0.489

217.958

0.0627

44.837

MU area

$8.164 \times 10^{-6}$

2.008

0.0584

102.301

Temperature

0.398

72.303

$-8.132 \times 10^{-7}$

$-0.787$

0.0518

37.018

Table 5:

\begin{tabular}{lll} 
Variable & Estimates & t-statistics \\
\hline Intercept & 4.742 & 21.780 \\
$\mathrm{SFP}_{\mathrm{M}}$ & -0.973 & -31.619 \\
$\mathrm{SFP}_{\mathrm{H}}$ & 0.0606 & 2.357 \\
Warming & -1.323 & -86.538 \\
MU area & $-8.787 \times 10^{-5}$ & -4.080 \\
Temperature & -0.672 & -23.396
\end{tabular}




\section{FIGURES}

Figure 1

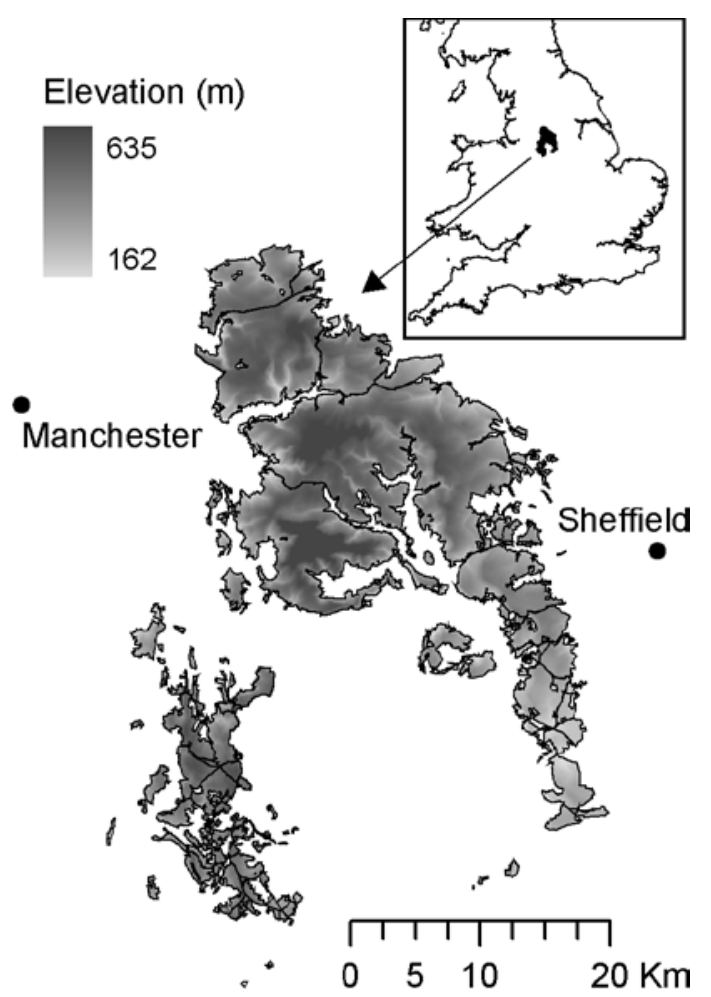


Figure 2

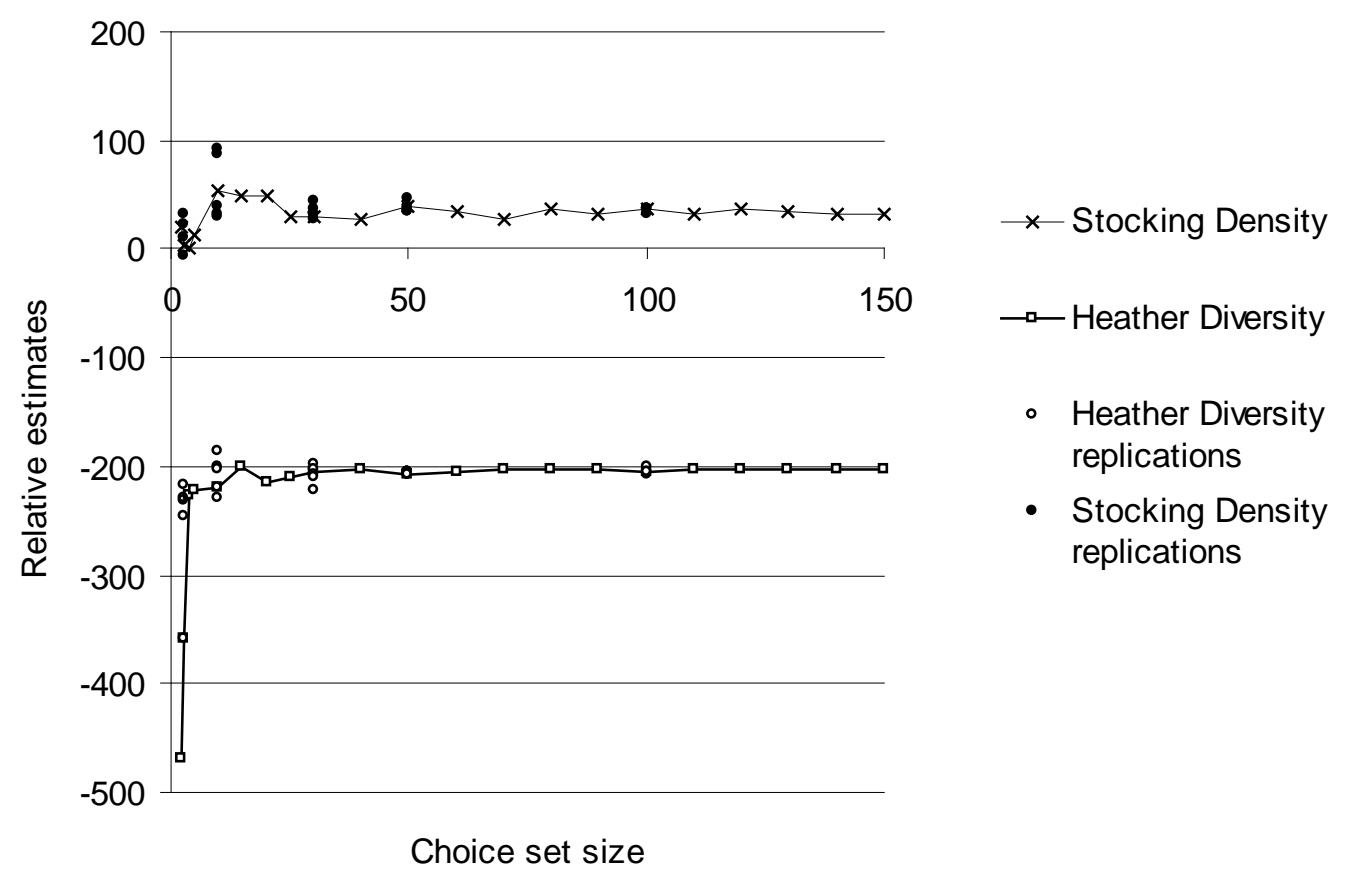


Figure 3

(a)

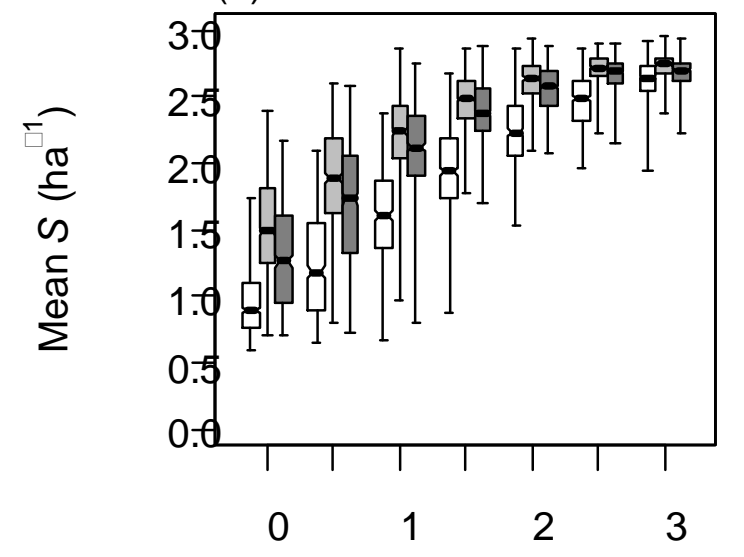

Increase in temf

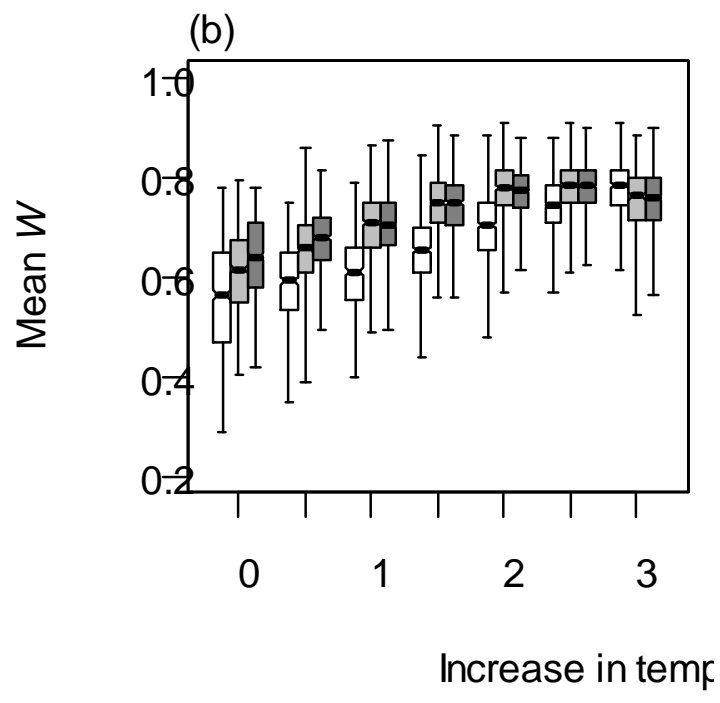


Figure 4
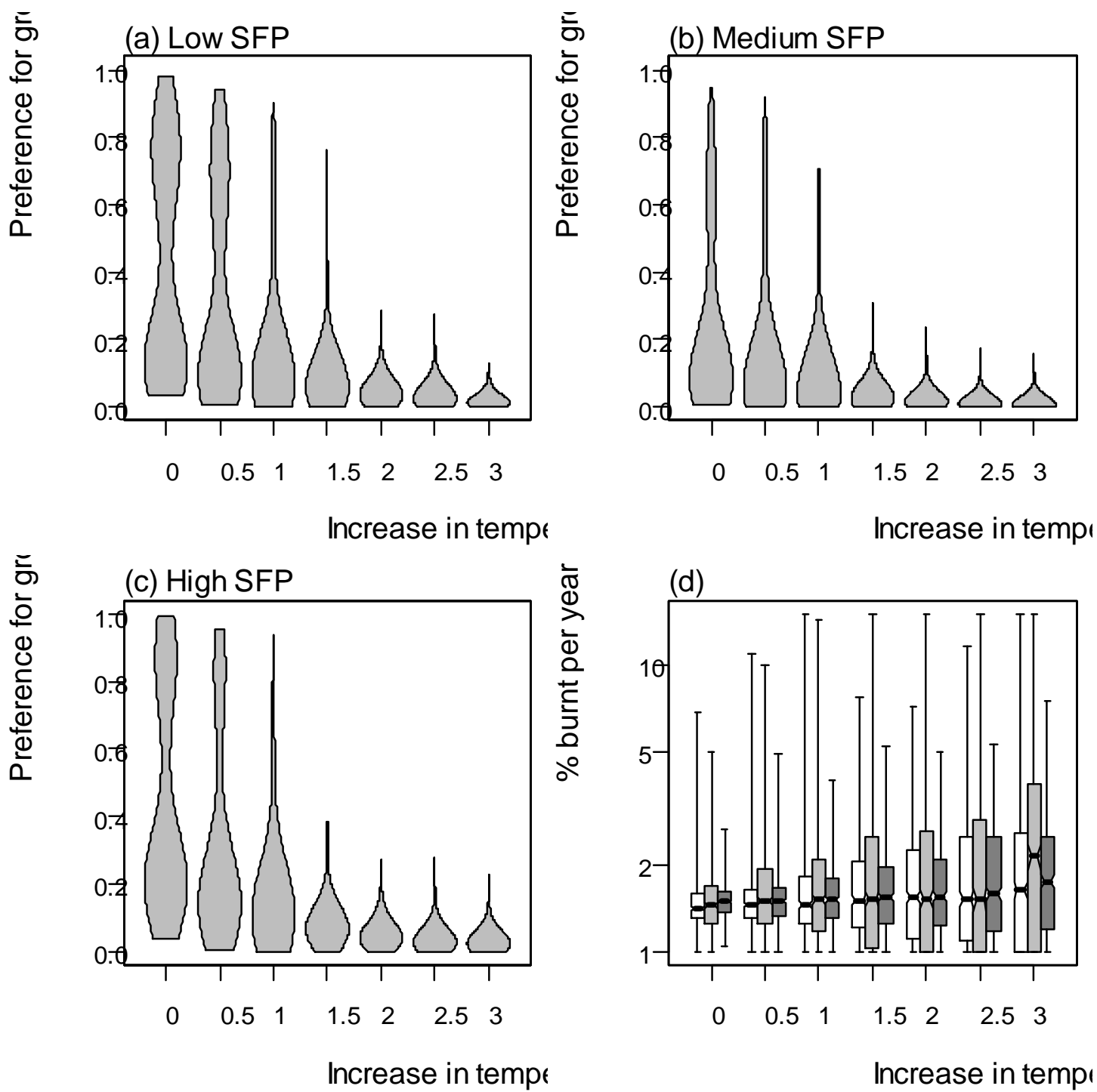
Figure 5:

(a) Dwarf shrub
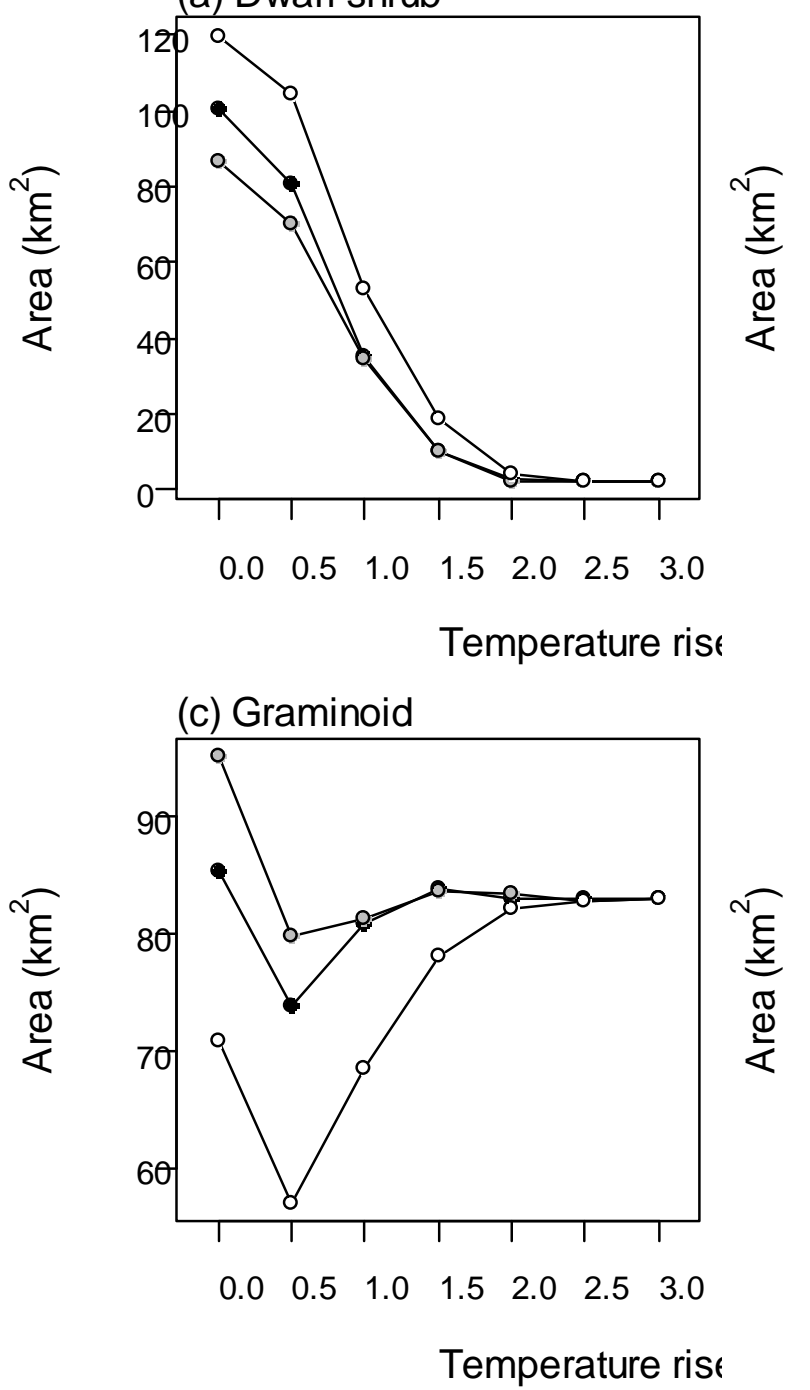

(b) Bracken

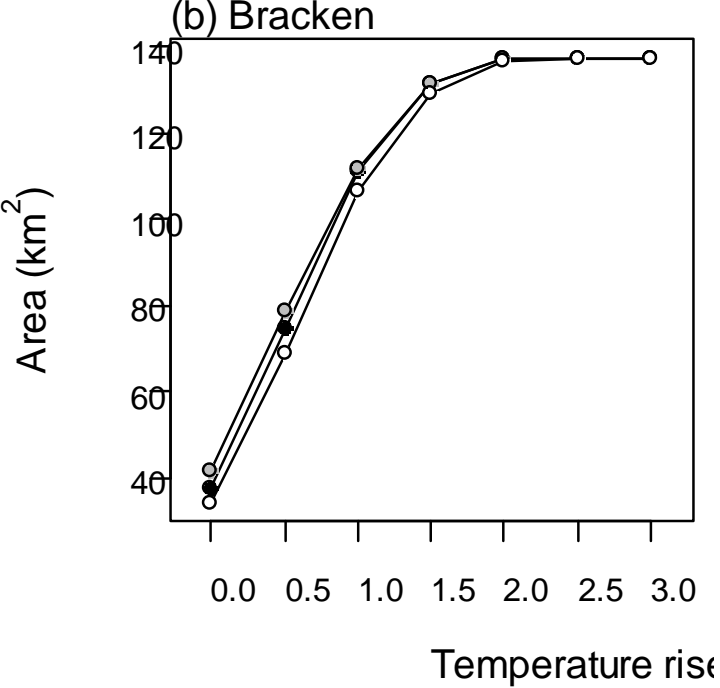

(d) Bare peat

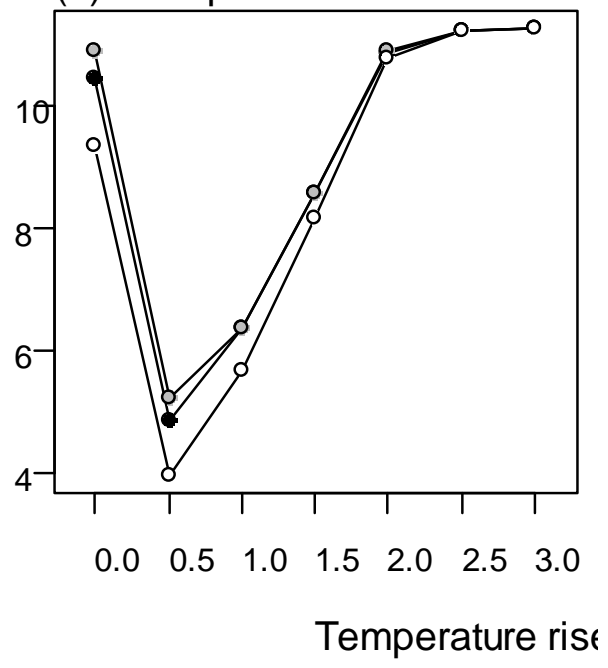




\section{CAPTIONS}

\section{TABLES}

Table 1: Data tested for the specification of the behavioural model

Table 2: Data used to run the habitat succession model

Table 3: Behavioural model specification (Choice set 100 alternative land management regimes)

Table 4: Determinants of summer and winter stocking densities in land management units. Summer stocking density model, $\mathrm{R}^{2}$ adj $=0.8161, P<0.001$. Winter stocking density model, $\mathrm{R}^{2}$ adj $=0.5161, P<0.001$.

Table 5: Binomial linear model of participation in managed burning. $\mathrm{R}^{2}$ adj $=0.405$. Correction for over dispersion, $k=78.68075$

\section{FIGURE}

Figure 1: Map of the open moorland within the Peak District and its location in Great Britain. To preserve confidentiality we are unable to show the exact location of the modelled management units.

Figure 2: Relative parameter estimates in choice model related to stocking density $\beta_{3}^{1} / \beta_{1}^{3}$ and related to heather density $\beta_{2}^{1} / \beta_{1}^{2}$ as a function of choice set size. Replication of estimations shown for choice set size $3,10,30,50,100$, five replications for each choice set size.

Figure 3: Responses of grazing strategies to joint variation in the single farm payment (SFP) and climate change. Boxplots show equilibrium (a) summer sheep densities $S$ $\left(\mathrm{ha}^{-1}\right.$ ) and (b) winter stocking rates $W$ (white, SFP $<£ 20$ ha-1; light grey, $£ 20<$ SFP $<$ $£ 60$ ha-1; dark grey, SFP > $£ 60 \mathrm{ha}^{-1}$ ). Boxplots show medians (thick lines), interquartile ranges (IQRs, boxes), ranges (whiskers) and $\pm 1.58 \mathrm{IQR} / \sqrt{ } n$ (notches) where $n=$ number of datapoints of values for the mean values of individual management units. . If 2 notches do not overlap, this indicates that the medians are significantly different at $P<0.05$. Mean values for each management unit are calculated from the strategies chosen during 500 simulated years, following an initial 500-year transient period. Values from ten replicate simulations are used in the plots.

Figure 4: (a-c) Violin plots showing the kernel density (indicated by width) of preference for grouse moor management for different temperature rises and levels of the single farm payment (SFP). Preference is measured as the proportion of years in which management units employ a strategy involving burning. (d) Boxplot of the mean percentage of the dwarf shrub burnt each year when management units employ strategies including burning, for variations in the single farm payment and climate change (all as in Figure 3). 
Figure 5: Mean equilibrium areas of (a) dwarf shrub, (b) bracken, (c) graminoids and (d) bare peat for differing temperature rise and single farm payments (white $=$ low, grey $=$ medium, black $=$ high). Means are values from ten replicate simulations after 1000 years. 